\title{
Recurrent Combined Thymic Epithelial Neoplasm
}

National Cancer Institute

\section{Source}

National Cancer Institute. Recurrent Combined Thymic Epithelial Neoplasm. NCI

Thesaurus. Code C115444.

The reemergence of combined thymic epithelial neoplasm after a period of remission. 